\title{
Alzheimer's Disease: Metabolic Uncoupling of Associative Brain Regions
}

\author{
Stanley I. Rapoport, Barry Horwitz, James V. Haxby and Cheryl L. Grady
}

\begin{abstract}
Evidence indicates that Alzheimer's disease (AD) causes functional disconnection of neocortical association areas. In mildly demented $\mathrm{AD}$ patients without measurable neocortically-mediated cognitive abnormalities, positron emission tomography demonstrates reduced parietal lobe glucose metabolism and left/right metabolic asymmetries in neocortical association areas. Similar metabolic abnormalities occur in moderately demented patients, but are accompanied by appropriate language and visuospatial discrepancies. Left/right metabolic asymmetries correspond with reduced numbers of partial correlations between metabolic rates in homologous right and left regions, and in the frontal and parietal cortices, indicating metabolic uncoupling among these regions. The affected association regions are those which demonstrate Alzheimer-type neuropathology post-mortem.
\end{abstract}

\begin{abstract}
RÉSUMÉ: Maladie d'Alzheimer: découplement métabolique des régions associatives du cerveau. Les données expérimentales indiquent que la maladie d'Alzheimer (MA) produit une déconnexion fonctionnelle des aires associatives du néocortex. Chez les patients atteints de MA et présentant une démence légère sans anomalie cognitive à médiation néocorticale mesurable, la tomographie à émission de positrons montre que le métabolisme du glucose est diminué au niveau du lobe pariétal et qu'il existe des asymétries métaboliques gauche/droite au niveau des aires associatives du néocortex. Des anomalies métaboliques similaires surviennent chez les patients modérément déments; elles sont alors accompagnées de discordances correspondantes au niveau du langage et de la perception visuospatiale. Les asymétries métaboliques droites et gauches et dans les cortex frontaux et pariétaux, indiquant un découplement métabolique entre ces régions. Les régions associatives atteintes sont celles qui présentent une neuropathologie de type Alzheimer en post-mortem.
\end{abstract}

Can. J. Neurol. Sci. 1986; 13:540-545

Alzheimer's disease (AD) is a progressive degenerative brain disorder that has no agreed-upon cause. The earliest and most prominent neuropsychological deficit is recent memory impairment, which usually is attributed to pathological and neurochemical changes in the hippocampus, amygdala and neocortex. ${ }^{1-3}$ The first cognitive deficits to appear that are related to neocortical dysfunction are impairments of abstract reasoning, language and visuospatial construction. ${ }^{4-6}$

Post-mortem studies indicate that the neuropathology characteristic of AD (senile plaques, neurofibrillary tangles) appears routinely in the hippocampus and very frequently in neocortical association areas, but rarely in perirolandic sensorimotor, auditory or visual cortices. ${ }^{1,3}$ However, the extent to which these regions show functional defects early in the course of $A D$ is not completely understood. Recently, the method of positron emission tomography (PET) has made it possible to measure cerebral metabolism and blood flow in cortical as well as subcor- tical regions of the human brain, and thereby to evaluate cerebral functional activity in AD.

To measure regional cerebral metabolic rates for glucose $\left(\mathrm{rCMR}_{\mathrm{glc}}\right)$, the positron-emitting isotope, ${ }^{18} \mathrm{~F}$-2-fluoro-2deoxy-D-glucose $\left({ }^{18} \mathrm{FDG}\right)$ is injected intravenously. Plasma radioactivity and glucose concentration are determined periodically thereafter and, after about $45 \mathrm{~min}$, regional brain radioactivity is determined with PET in horizontal cross-sections of the brain. ${ }^{18} \mathrm{FDG}$ is phosphorylated within the brain, but is not further metabolized nor rapidly dephosphorylated, due to a low activity of phosphatase. Its rate of accumulation is used to calculate $\mathrm{rCMR}_{\mathrm{glc}}$ and to reconstruct images of the brain. ${ }^{7}$

In this article is summarized data obtained with PET by the Laboratory of Neurosciences, that describe the early and progressive disruption of the associative structures of the brain in the patients with $A D$, and the neuropsychological deficits that correlate with this disruption. 
Primary sensory areas (visual, somatosensory and auditory) and the primary motor area of the neocortex are connected to adjacent association fields in the parietal, frontal (premotor) and temporal lobes. These association fields are in turn connected reciprocally with the prefrontal cortex, and with paralimbic and limbic areas (including the hippocampus and parahippocampal gyrus), the latter connections investing information with emotional tone and placing it in long-term memory. ${ }^{8.9}$ Association neurons in the frontal cortex, found mainly in layer III and to a lesser extent in layers IV and V, are reciprocally connected with ipsilateral parietal association neurons, and with contralateral homologous association neurons via the corpus callosum, that integrate right and left hemispheric activities. ${ }^{10}$ Ipsilateral and contralateral association fibers terminate in neocortical association areas in distinct vertically oriented columns, 250 to $750 \mu \mathrm{m}$ in diameter. $"$

\section{Brain Metabolism in Alzheimer's Disease (AD)}

Duara et al. ${ }^{12}$ examined $\mathrm{rCMR}_{\mathrm{glc}}$ in relation to severity of dementia in $21 \mathrm{AD}$ patients and in 29 age-matched healthy controls. PET was performed with limited sensory stimulation (eyes covered, ears plugged with cotton) in a quiet room when the subject was at rest. Patients were screened for illnesses other than $\mathrm{AD}$ which might contribute to cerebral dysfunction. $\mathrm{AD}$ (possible or probable) was diagnosed according to NINCDSADRDA criteria for choosing patients for research purposes. ${ }^{13}$ Severity of dementia was assessed with the Mini-Mental State Examination: ${ }^{14}$ mild, score $=\geqslant 21$; moderate, score $=11-20$; severe, score $=0-10$.

Significant differences in $\mathrm{rCMR}_{\mathrm{glc}}$ between $\mathrm{AD}$ patients and controls occurred in the severely demented but not mildly or moderately demented $\mathrm{AD}$ patients, in the frontal, parietal and temporal lobes (Table 1). ${ }^{12}$ All AD patient groups had a reduced ratio of parietal to sensorimotor $\mathrm{rCMR}_{\text {glc }}$ (used as reference because of its minimal neuropathology and metabolic dysfunction in AD), as compared with controls. A later study showed reduction of the temporal/occipital $\mathrm{rCMR}_{\text {glc }}$ ratio as well. ${ }^{5}$

Friedland, et $\mathrm{a}^{15}$ also found that within-subject ratios of metabolic rates are more sensitive indicators of cerebral metabolic disorders in AD than are the regional rates by themselves. On the other hand, Foster, et al ${ }^{16}$ reported significant $24 \%$ to $42 \%$ reductions in $\mathrm{rCMR}_{\mathrm{glc}}$ in the frontal, parietal, temporal and occipital lobes in mildly as well as severely demented $A D$ patients as compared with controls. We believe that their reductions are overestimated, because the control $\mathrm{rCMR}_{\mathrm{glc}}$ values in their study were from a small sample $(\mathrm{N}=7)$ and appear unreasonably elevated.

\section{Asymmetry of Brain Metabolism and Cognitive Discrepancy in $\mathrm{AD}$}

To look for small differences in neocortical metabolism, Haxby, et al ${ }^{4}$ defined a metabolic asymmetry index (\%) for homologous right and left brain regions,

$$
\text { Asymmetry Index }=\frac{\mathrm{rCMR}_{\mathrm{glc} . \text { right }}-\mathrm{rCMR}_{\mathrm{gtc} \text {, left }}}{\left[\mathrm{rCMR}_{\mathrm{glc} \text {.right }}+\mathrm{rCMR}_{\text {glc.left }}\right] / 2} \times 100(1)
$$

Asymmetry indices were calculated for 10 mildly and moderately demented $\mathrm{AD}$ patients and for 26 healthy controls, from $\mathrm{rCMR}_{\text {glc }}$ data obtained with PET (Figure 1). No difference between patients and controls was found for mean metabolic asymmetries in any of 5 neocortical regions, indicating that the $\mathrm{AD}$ patients did not have a consistently reduced right-sided or left-sided metabolism. However, AD patients had significantly greater variances of asymmetry (S.D. ${ }^{2}$ ) than did controls in the frontal, parietal and temporal association cortices $(p<0.01)$, but not in sensorimotor or occipital cortices ( $p>0.05)$.

Studies of patients with focal brain damage suggest that syntax comprehension, mental arithmetic and immediate verbal memory are related to left parietal and temporal function, whereas visuospatial construction is related to right parietal function. ${ }^{4.5}$ To see if metabolic asymmetries in AD corresponded to appropriate neocortically mediated cognitive deficits, Haxby, et a ${ }^{4}$ used a Syntax Comprehension Test to examine left neocortical function, and an Extended Range Drawing Test to examine right neocortical function. AD patients were ranked separately on the test scores; the difference between the ranks was calculated as a "syntax/drawing discrepancy." A WAIS index of neuropsychological discrepancy also was derived, as the difference between WAIS factor scores summarizing performance on tests of visuospatial construction, and on tests of mental arithmetic and immediate verbal memory.

Both indices of neuropsychological discrepancy were correlated significantly and appropriately with metabolic asymmetry in the cerebral hemispheres (Table 2). The syntax/drawing index also was correlated significantly with metabolic asymmetries in the frontal and parietal association cortices, such

Table 1: Left lobar metabolic rates and metabolic quotients for patients with AD of varying severity, and for controls. Data are from Duara, et al. ${ }^{12}$

\begin{tabular}{|c|c|c|c|c|}
\hline \multicolumn{5}{|c|}{$\mathrm{rCMR}_{\mathrm{glc}}, \mathrm{mg} \cdot 100 \mathrm{~g}^{-1} \cdot \mathrm{min}^{-1}$} \\
\hline Temporal lobe & $4.48 \pm 1.12$ & $3.37 \pm 0.81$ & $4.13 \pm 0.90$ & $2.46 \pm 0.74^{\mathrm{b}}$ \\
\hline Occipital lobe & $5.31 \pm 1.30$ & $4.43 \pm 1.15$ & $5.71 \pm 0.97$ & $4.21 \pm 0.78$ \\
\hline Sensorimotor cortex & $5.59 \pm 1.55$ & $4.81 \pm 1.19$ & $5.59 \pm 1.00$ & $3.83 \pm 0.91$ \\
\hline \multicolumn{5}{|c|}{$\mathbf{r C M R}_{\mathrm{gld}} /\left(\right.$ sensorimotor $\left.\mathrm{rCMR}_{\mathrm{glc}}\right)$} \\
\hline Frontal lobe & $0.95 \pm 0.07$ & $0.96 \pm 0.08$ & $0.92 \pm 0.07$ & $0.91 \pm 0.23$ \\
\hline Parietal lobe & $0.98 \pm 0.07$ & $0.88 \pm 0.03^{\mathrm{b}}$ & $0.83 \pm 0.12^{\mathrm{b}}$ & $0.67 \pm 0.05^{\mathrm{b}}$ \\
\hline Temporal lobe & $0.83 \pm 0.15$ & $0.72 \pm 0.15$ & $0.74 \pm 0.12$ & $0.62 \pm 0.06^{\mathrm{b}}$ \\
\hline Occipital lobe & $0.98 \pm 0.15$ & $0.93 \pm 0.11$ & $1.03 \pm 0.15$ & $1.09 \pm 0.09$ \\
\hline
\end{tabular}

"Number of patients in parenthesis.

${ }^{\circ}$ Mean \pm S.E. significantly different from control $(p<0.05$, Bonferroni $t$ test $)$. 
that lower left-sided $\mathrm{rCMR}_{\mathrm{glc}}$ corresponded to worse language function, and lower right-sided $\mathrm{rCMR}_{\mathrm{glc}}$ to worse visuoconstructive function. In contrast, the WAIS discrepancy index was not correlated with metabolic asymmetry in the healthy controls. The results indicate that metabolic asymmetries in mildly-to-moderately demented AD patients correspond to discrepancies between language and visuospatial deficits as expected from known functional neuroanatomy.
To see if metabolic asymmetry precedes or follows neocortically mediated cognitive differences in the course of $A D$, both parameters were evaluated in $\mathrm{AD}$ patients divided according to severity of dementia. ${ }^{5}$ Table 3 presents neuropsychological test scores for control subjects and for AD patients with mild and moderate dementia. Moderately demented AD patients differed significantly from controls on all of the neuropsychological measures, whereas the mildly demented patients differed only

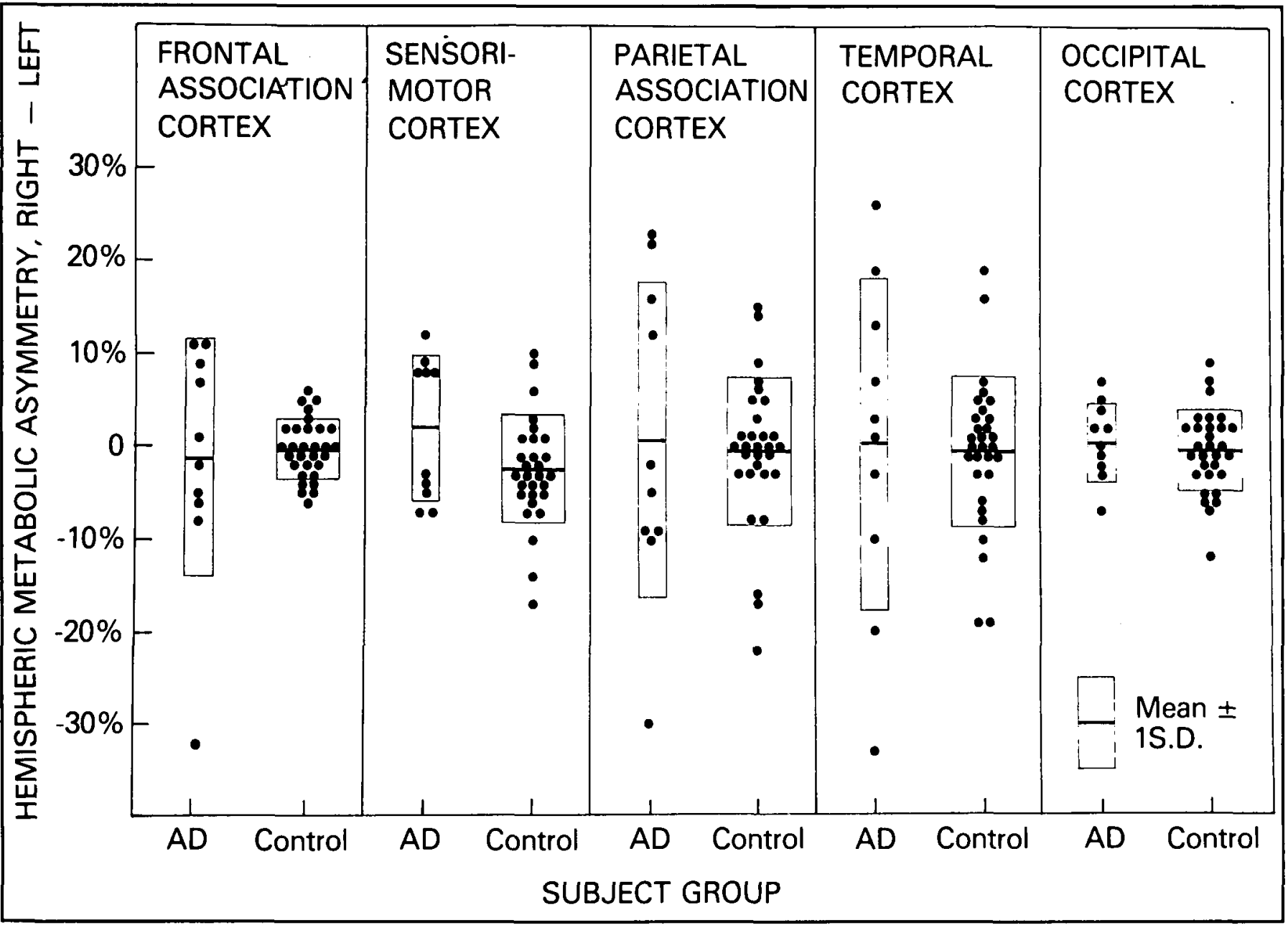

Figure 1 - Percentage differences between $r C M R_{g l c}$ in homologous right and left cerebral cortical regions for 10 Alzheimer's disease (AD) patients and 26 healthy controls. Positive scores correspond to higher right hemisphere metabolism. Data are from Haxby, et al.*

Table 2: Correlations between asymmetry of $\mathrm{rCMR}_{\mathrm{glc}}$ and discrepancies of language and visuospatial construction in mildly-to-moderately demented AD patients and in right-handed control subjects. Data are from Haxby, et al. ${ }^{4}$

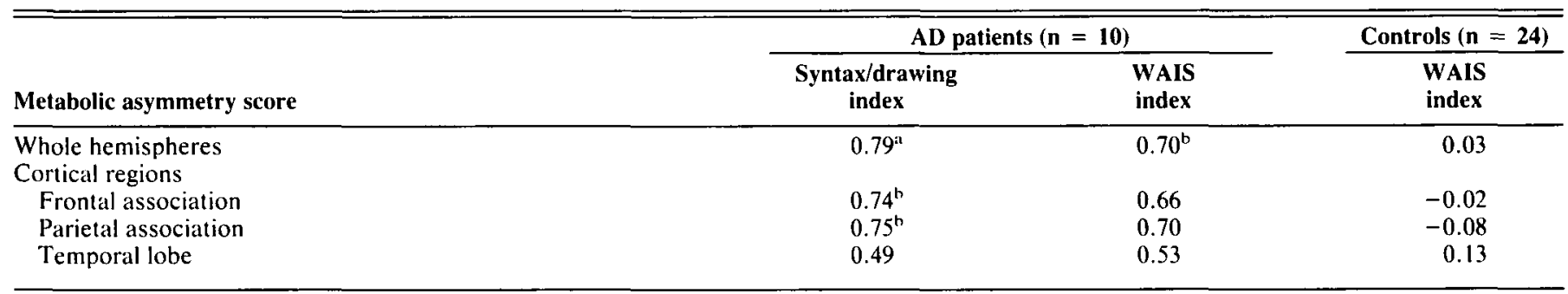

Positive correlations correspond to lower left-sided $\mathrm{rCMR}_{\mathrm{glc}}$ and worse language function, or lower right-sided $\mathrm{rCMR}_{\mathrm{glc}}$ and worse drawing ability.

WAIS, Wechsler Adult Intelligence Scale.

"i $p<0.01:{ }^{b} p<0.05$. 
on tests of memory $(\mathrm{p}<0.01)$. A significant and isolated memory impairment, with normal scores on all tests of language and visuospatial functions, characterized 5 of the 10 mildly demented patients.

Despite their normal scores, these mildly demented patients demontrated increased neocortical metabolic asymmetries (Table 4), just as did the moderately demented patients. Neuropsychological discrepancies between language and visuospatial function were highly correlated in the appropriate direction with metabolic asymmetries in the moderately demented but not in the mildly demented patients. These results indicate that neocortical metabolic dysfunction can precede measurable neocortically-mediated cognitive deficits in $\mathrm{AD}$.

Both right/left asymmetries of $\mathrm{rCMR}_{\mathrm{glc}}$, and neocortically mediated cognitive discrepancies, remain stable and appropriately correlated over time in individual AD patients. ${ }^{17}$ In 16 patients who were mildly or moderately demented at their first examination, only 2 showed small reversals in cognitive discrepancy (syntax/visuoconstructive index) on their second examination within 6 months to 2 years of the first, but none reversed the sign of the statistically significant metabolic asymmetry, if present (index $>2$ S. D. from control value). Metabolic asymmetries and cognitive discrepancies remained highly correlated at the first and second examinations, suggesting a consistent and frequently asymmetric pathological process within the Alzheimer brain.

Metabolic asymmetry in mildly and moderately demented AD patients is accompanied by reduced integration of func- tional activities between ipsilateral parietal and frontal regions, and between homologous right and left hemisphere regions. This was demonstrated by Horwitz, et al, ${ }^{18}$ who determined partial correlation coefficients between $\mathrm{rCMR}_{\mathrm{glc}}$ values in pairs of brain regions examined with PET, after correcting for global $\mathrm{CMR}_{\mathrm{glc}}$ to eliminate its common influence on regional metabolism. A total of 59 regions were evaluated (1711 pairs), and statistically significant $(\mathrm{p}<0.025)$, "reliable" partial correlations ${ }^{19}$ were displayed in individual matrices (Figure 2) for 21 mildly and moderately demented AD patients and 21 agematched controls. Regions in the matrices were arranged according to their anatomicál locations.

As illustrated by Figure 2 and Table 5, the number of reliable correlation coefficients at $p<0.025$ was reduced in the right and left ipsilateral frontal-parietal domains and between homologous right and left brain regions (in diagonals between right and left lobar submatrices) in the AD patients as compared with controls. Fewer reliable correlations in the frontal and parietal lobes continue a trend found between old and young healthy men. ${ }^{19}$ Fewer correlations between right and left regions may reflect their reduced functional coupling via subcortical structures such as the nucleus basalis of Meynert, ${ }^{18.20}$ or via the corpus callosum. Indeed, corpus callosotomy in rats reduces the values of partial correlation coefficients between homologous cortical regions. ${ }^{21}$

Our findings of reduced integrated activity in AD are opposite to those of Metter, et al, ${ }^{22}$ who reported increased numbers of partial correlations in AD patients (43 as compared to 17 in

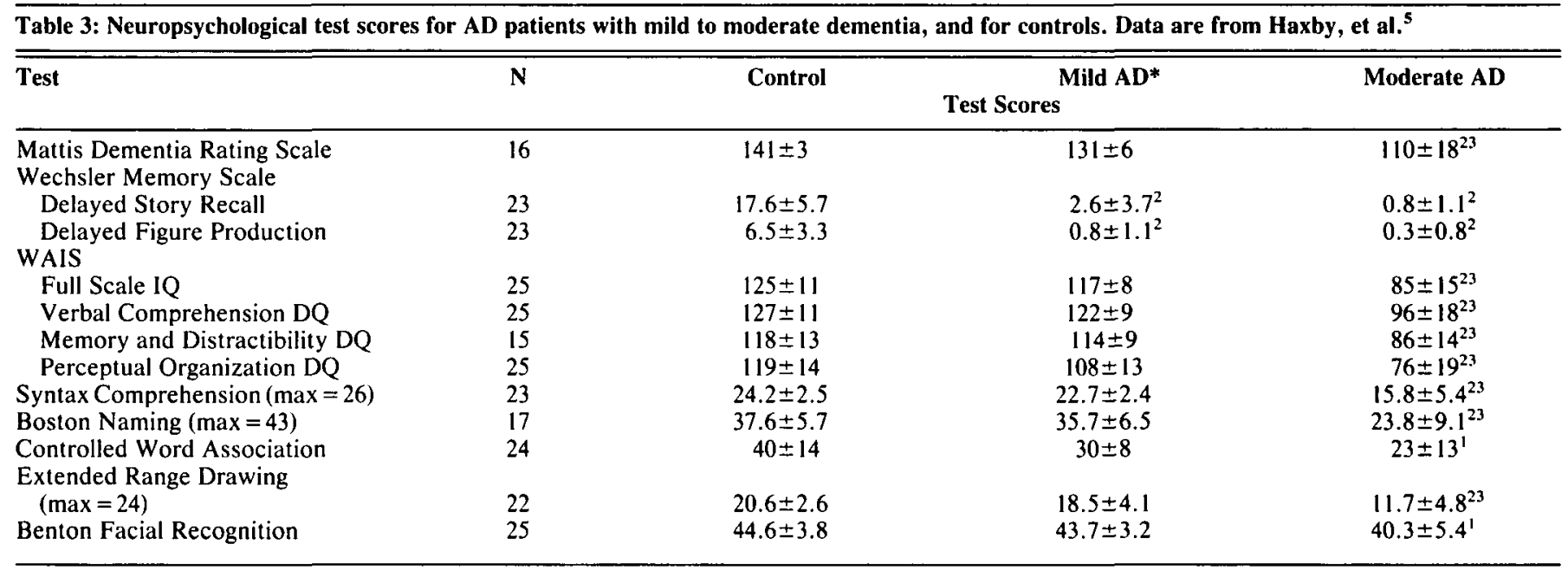

*Means \pm S.D. in 10 mildly and 12 moderately demented patients.

Significantly less than control mean: ${ }^{1}, p<0.01 ;{ }^{2}, p<0.001$.

${ }^{3}$ Mean significantly less than in mild AD, $p<0.001$.

$\mathrm{DQ}=$ Factor Deviation Quotient.

$\mathrm{N}=$ number of control subjects for each test

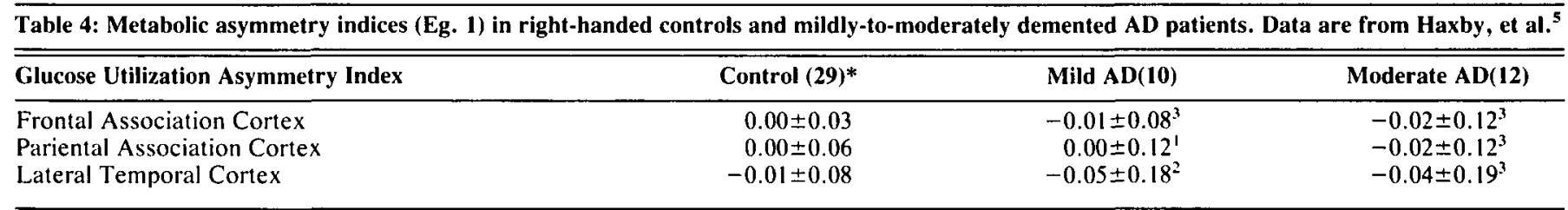

*Means \pm S.D. are given (number of subjects in parenthesis).

Variance is greater than in controls: ${ }^{1} \mathrm{p}<0.05 ;{ }^{2} \mathrm{p}<0.01 ;{ }^{3} \mathrm{p}<0.001$. 
controls), together with a decline in global metabolism, and concluded that functional independence between brain regions is lost in AD.

\section{Conclusions}

These studies suggest that post-mortem neuropathology in AD (senile plaques, neurofibrillary tangles), distributed in the neocortical association areas and hippocampal formation, corresponds to altered functional activity in these same regions very early in the course of the dementia. The data indicate that $\mathrm{AD}$ causes a progressive and asymmetrical disturbance in neocortical association areas, resulting in their functional disconnection.

Functional disturbance of the hippocampal formation, which probably occurs in mildly demented AD patients with only a memory defect, is not easily demonstrated with PET because of partial voluming artifacts and the poor resolution of available scanners. However, post-mortem studies indicate that the hippocampal formation always is affected in $\mathrm{AD}^{2.23}$ particularly in layers II and III of the entorhinal cortex and in the subiculum and CAl regions of the hippocampus. These areas connect the hippocampal formation reciprocally with the association neocortices, basal forebrain, thalamus and hypothalamus, and their involvement in $\mathrm{AD}$ may functionally remove the hippocampal formation from the cerebral association system. ${ }^{23}$

AD patients display neocortical metabolic abnormalities, reduced temporal and parietal metabolism referenced to metabolism in the sensorimotor or occipital cortex, and increased left-right metabolic asymmetries in neocortical associative areas, which correlate with neocortically mediated cognitive discrepancies in moderate but not mild dementia. Thus, metabolic dysfunction in the associative neocortices precedes measurable cognitive deficits, which may allow PET to be used to diagnose and follow $A D$ in its early stages. The metabolic asymmetries correspond with reduced functional interactions between ipsilateral parietal and frontal regions and between contralateral homologous regions, as determined by the correlation matrix method, and are consistent with neuropathological studies suggesting disruption of intracortical communication. . $^{3.24}$

The constancy of metabolic asymmetries and of appropriate cognitive discrepancies in individual $A D$ patients, in repeated measures with an average separation of 15 months, ${ }^{17}$ suggests that both parameters are related to asymmetrical and long-

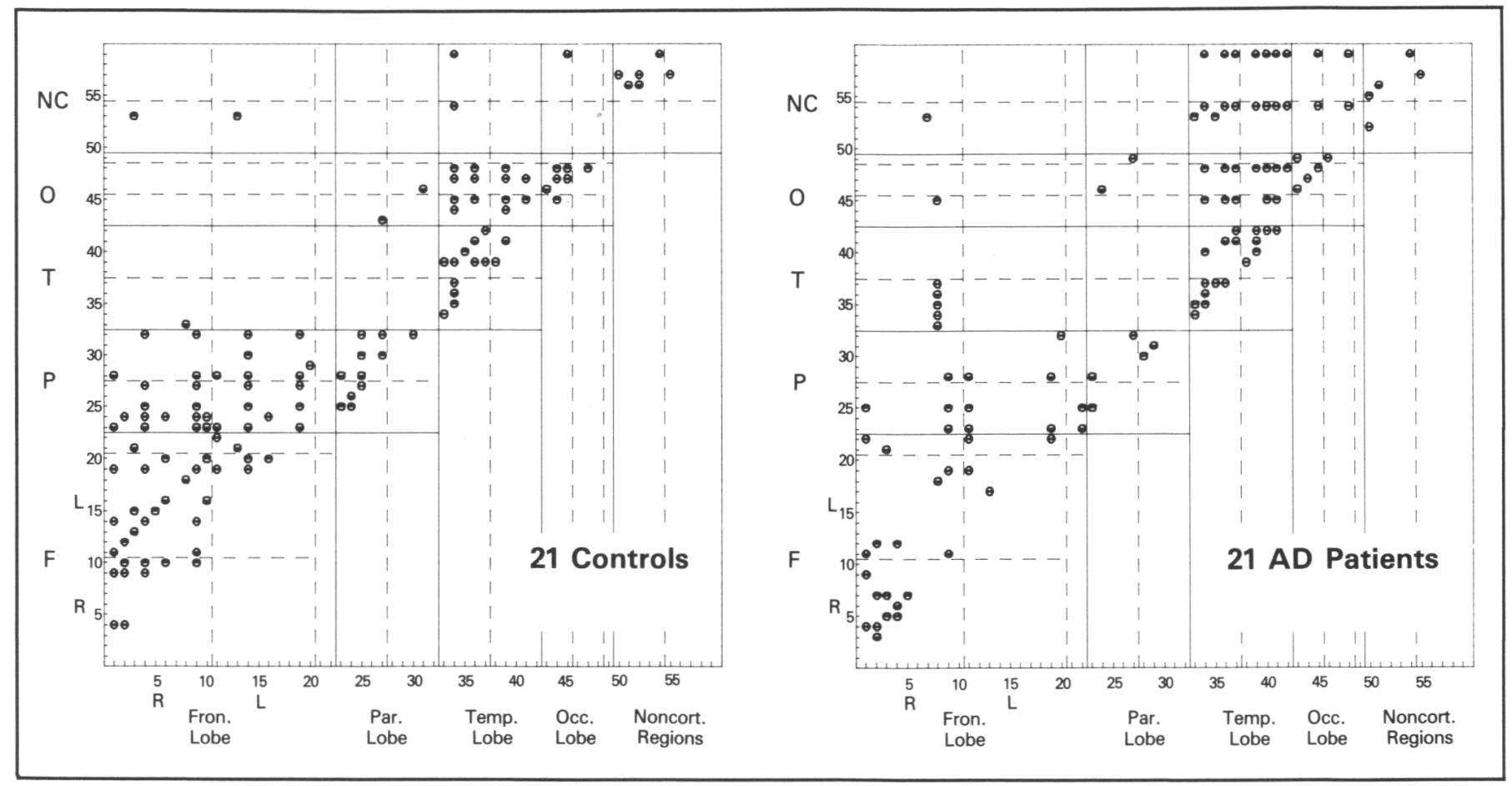

Figure 2 - Matrices of positive partial correlation coefficients between pairs of $r C M R_{\text {glc }}$ values for 21 control and 21 AD subjects. Reliable correlations $(r>0.5, p<0.025)$ are illustrated. Regions are arranged according to whether they fall in the left $(L)$ or right $(R)$ frontal $(F)$, parietal $(P)$, temporal $(T)$, occipital $(O)$ or noncortical $(N C)$ domains. Data are from Horwitz, et al, ${ }^{18}$ where definitions and identities of regions are provided.

Table 5: Statistically significant differences in number of "reliable" partial correlation coefficients (statistically significant at p<0.025) between whole brain matrices from 21 mildly-to-moderately demented AD patients and from 21 controls. Data are from Horwitz, et al. ${ }^{18}$

\begin{tabular}{lccc}
\hline & & \multicolumn{2}{c}{ Number of Reliable Partial Correlations } \\
\cline { 2 - 5 } Correlated Regions & Total Possible & Control Subjects & 32 \\
Frontal-Parietal & 220 & 22 & $12^{*}$ \\
Homologous (Right/Left) & 28 & $14^{*}$ & AD Patients \\
\hline
\end{tabular}

*Significantly different from control by $\chi^{2}(p<0.05)$.

Matrices were derived from rCMR $\mathrm{glc}_{\mathrm{c}}$ values in $21 \mathrm{AD}$ patients and 21 healthy controls. 
standing pathology involving the association neocortices. Indeed, these asymmetrical functional defects may correspond to the asymmetrical distribution of senile (neuritic) plaques in the association cortices of the post-mortem AD brain. ${ }^{20}$ The latter asymmetries, in turn, appear to be associated with asymmetrical losses of large cholinergic neurons in the nucleus basalis of Meynert, which provides a large fraction of cholinergic innervation to the neocortical association cortices. ${ }^{20}$

Pathology of associative cerebral structures also is suggested by the fact that the thickness of the temporal cortex is not reduced significantly in AD brains, ${ }^{25}$ whereas volume and length are reduced in relation to ante mortem severity of dementia. ${ }^{26}$ These observations indicate columnar rather than laminar involvement, and are consistent with the columnar organization of receptor fields of cortical association neurons (see above). " Furthermore, the predilection of senile (neuritic) plaques for layers III and IV of the association cortices ${ }^{3,24}$ corresponds to the distribution of large pyramidal cells subserving associational inputs and outputs, ${ }^{11}$ many of which are lost in $\mathrm{AD} .{ }^{25}$ Disruption of association neurons and axons in $A D$ may be caused by cytoskeletal pathology, resulting in disturbed axonal transport of neurofilaments and axonal dystrophy. ${ }^{27}$

\section{REFERENCES}

1. Brun A, Gustafson L. Distribution of cerebral degeneration in Alzheimer's disease. A clinico-pathological study. Arch Psychiat Nervenkr 1976; 223: 15-33.

2. Ball MJ, Fisman M, Hachinski V, et al. A new definition of Alzheimer's disease: a hippocampal dementia. Lancet Jan., 1985; 14-16.

3. Pearson RCA, Esiri MM, Hiorns RW, et al. Anatomical correlates of the distribution of the pathological changes in the neocortex in Alzheimer's disease. Proc Natl Acad Sci 1985; 82: 4531-4534.

4. Haxby JV, Duara R, Grady CL, et al. Relations between neuropsychological and cerebral metabolic asymmetries in early Alzheimer's disease. J Cerebr Blood Flow Metab 1985; 5: 193-200.

5. Haxby JV, Grady CL, Duara R, et al. Neocortical metabolic abnormalities precede non memory cognitive deficits in early Alzheimer's-type dementia. Arch Neurol 1986; 43: 882-885.

6. Grady $\mathrm{CL}$, Haxby J, Sundaram M, et al. Longitudinal relations between cognitive and cerebral metabolic deficits in Alzheimer's disease (AD). J Clin Exp Neuropsychol 1985; 7: 622.

7. Huang S-C, Phelps ME, Hoffman EJ, et al. Noninvasive determination of local cerebral metabolic rate of glucose in man. Am J Physiol 1980; 238: E69-E82.

8. Pandya DN, Seltzer B. Assocation areas of the cerebral cortex. Trends Neurosci 1982; 5: 386-390.

9. Van Hoesen GW. The parahippocampal gyrus. New observations regarding its cortical connections in the monkey. Trends Neurosci 1982; 5 : $345-350$
10. Schwartz ML, Goldman-Rakic PS. Callosal and intrahemispheric connectivity of the prefrontal association cortex in Rhesus monkey: relation between intraparietal and principal sulcal cortex. J Comp Neurol 1984; 226: 403-420.

11. Goldman PS, Nauta WJH. Columnar distribution of cortico-cortical fibers in the frontal association, limbic, and motor cortex of the developing Rhesus monkey. Brain Res 1977; 122: 393-413.

12. Duara R, Grady C, Haxby J, et al. Positron emission tomography in Alzheimer's disease. Neurol 1986; 36: 879-887.

13. McKhann G, Drachman D, Folstein M, et al. Clinical diagnosis of Alzheimer's disease: Report of the NINCDS-ADRDA Work Group under the auspices of Department of Health and Human Services Task Force on Alzheimer's disease. Neurol 1984; 34: 939-944.

14. Fostein MF, Folstein SE, McHugh PR. "Mini-Mental State". A practical method for grading the cognitive state of patients for the clinician. J Phychiat Res 1975; 12: 189-198.

15. Friedland RP, Budinger TF, Koss E, et al. Alzheimer's disease: anterior-posterior and lateral hemispheric alterations in cortical glucose utilization. Neurosci Lett 1985; 53: 235-240.

16. Foster NL, Chase TN, Mansi L, et al. Cortical abnormalities in Alzheimer's disease. Ann Neurol 1984: 16: 649-654.

17. Grady CL, Haxby JV, Schlageter NL, et al. Stability of metabolic and neuropsychological asymmetries in dementia of the $\mathrm{Alz}$ heimer type. Neurol (in press).

18. Horwitz B, Grady CL, Schlageter NL, et al. Intercorrelations of regional cerebral metabolic rates in Alzheimer's disease. Brain Res (in press).

19. Horwitz B, Duara R, Rapoport SI. Age differences in intercorrelations between regional cerebral metabolic rates for glucose. Ann Neurol 1986; 19: 60-67.

20. Arendt T, Bifl V, Tennstedt A, et al. Neuronal loss in different parts of the nucleus basalis is related to neuritic plaque formation in cortical target areas in Alzheimer's disease. Neurosci $1985 ; 14,1-14$.

21. Soncrant TT, Horwitz B, Sato S, et al. Left-right regional functional interactions are disrupted by corpus callosotomy in the rat. Abstr Soc Neurosci 1986; 12: 177.

22. Metter EJ, Riege WH, Kameyama M, et al. Cerebral metabolic relationships for selected brain regions in Alzheimer's, Huntington's, and Parkinson's diseases. J Cerebr Blood Flow Metab 1984; 4 : 500-506.

23. Hyman BT, Hoesen GWB, Damasio AR, et al. Alzheimer's disease: cell-specific pathology isolates the hippocampal formation. Science 1984; 225: 1168-1170.

24. Rogers J, Morrison JH. Quantitative morphology and regional and laminar distributions of senile plaques in Alzheimer's disease. J Neurosci 1985; 5: 2801-2808.

25. Terry RD, Peck A, DeTeresa R, et al. Some morphometric aspects of the brain in senile dementia of the Alzheimer type. Ann Neurol 1981; 10: 184-192.

26. Duyckaerts C, Hauw JJ, Piette F, et al. Cortical atrophy in senile dementia of the Alzheimer type is mainly due to a decrease in cortical length. Acta Neuropath (Berl) 1985; 66: $72-74$.

27. Gajdusek DC. Hypothesis: Interference with axonal transport of neurofilament as a common pathogenetic mechanism in certain diseases of the central nervous system. New Eng J Med 1985; 312: 714-719. 